\title{
Proposed Guidelines for Solid Phase Extraction of Suwannee River Dissolved Organic Matter
}

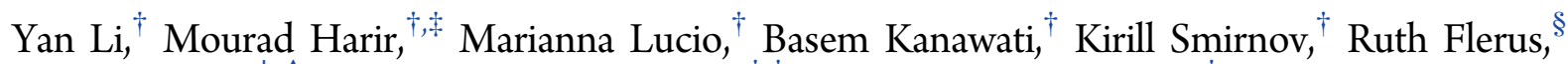
Boris P. Koch, ${ }^{\perp, \Delta}$ Philippe Schmitt-Kopplin, ${ }^{\dagger, \dagger}$ and Norbert Hertkorn ${ }^{*}, \dagger$

${ }^{\dagger}$ Research Unit Analytical Biogeochemistry (BGC), Helmholtz Zentrum München, German Research Center for Environmental Health, Ingolstädter Landstrasse 1, 85764 Neuherberg, Germany

${ }^{\ddagger}$ Chair of Analytical Food Chemistry, Technische Universität München, 85354 Freising, Germany

${ }^{\S}$ GEOMAR Helmholtz-Zentrum für Ozeanforschung Kiel, Düsternbrooker Weg 20, 24105 Kiel, Germany

${ }^{\perp}$ Alfred Wegener Institute for Polar und Marine Research, Am Handelshafen 12, 27570 Bremerhaven, Germany

${ }^{\Delta}$ Hochschule Bremerhaven, University of Applied Sciences, An der Karlstadt 8, 27568 Bremerhaven, Germany

\section{Supporting Information}

ABSTRACT: This paper proposes improved guidelines for dissolved organic matter (DOM) isolation by solid phase extraction (SPE) with a styrene-divinylbenzene copolymer (PPL) sorbent, which has become an established method for the isolation of DOM from natural waters, because of its ease of application and appreciable carbon recovery. Suwannee River water was selected to systematically study the effects of critical SPE variables such as loading mass, concentration, flow rate, and up-scaling on the extraction selectivity of the PPL sorbent. High-field Fourier transform ion cyclotron resonance mass spectrometry (FTICR MS) and proton nuclear magnetic resonance ( ${ }^{1} \mathrm{H}$ NMR) spectroscopy were performed to interpret the DOM chemical space of eluates, as well as permeates and wash liquids with molecular resolution. Up to $89 \%$ dissolved organic carbon (DOC) recovery was obtained with a DOC/PPL mass ratio of $1: 800$ at a DOC concentration of $20 \mathrm{mg} / \mathrm{L}$. With the application of larger loading volumes, low proportions of highly oxygenated compounds were retained on the PPL sorbent. The effects of the flow rate on the extraction selectivity of the sorbent were marginal. Up-scaling had a limited effect on the extraction selectivity with the exception of increased self-esterification with a methanol solvent, resulting in methyl ester groups. Furthermore, the SPE/ PPL extract exhibited highly authentic characteristics in comparison with original water and reverse osmosis samples. These findings will be useful for reproducibly isolating DOM with representative molecular compositions from various sources and concentrations and minimizing potential inconsistencies among interlaboratory comparative studies.
$\mathrm{D}$ issolved organic matter (DOM) is a complex mixture of organic molecules with $\sim 50 \%$ carbon content and various proportions of heteroatoms such as oxygen, nitrogen, phosphorus, and sulfur. ${ }^{1}$ DOM is one of the most abundant contributors to the global carbon pool, and it is actively involved in key aquatic ecosystem processes, ${ }^{2-4}$ such as biodegradation, ${ }^{5}$ heterotrophic transformation process, ${ }^{6}$ complexation with trace elements, ${ }^{7}$ and modification of bacterial metabolism. ${ }^{8}$ Because of its pivotal role in the environment, a growing number of biologists, ecologists, chemists, geologists, and bioinformaticians have conducted DOM characterization studies to decipher the global biogeochemical carbon cycling. $^{1-3}$

DOM isolation is essential, because it directly affects both dissolved organic carbon (DOC) recovery and the selectivity of recovered molecular structures, upon which all consecutive steps such as organic structural spectroscopy and data evaluation must exclusively rely. ${ }^{9-11}$ In the case of DOM characterization, consequences of erroneous sampling always exceed those resulting from inattentive analysis. Meanwhile,
DOM isolation should provide high yield for providing representative materials with limited bias to ensure authenticity. ${ }^{12-14}$ In sharp contrast to even the most complex mixtures of biomolecules extracted from living organisms, polydisperse biogeochemical supermixtures ${ }^{1}$ such as freshwater and marine DOM from water bodies cannot be resolved into individual molecules, as a result of the huge number $\left(>10^{6}\right)$ of diverse molecules present. ${ }^{1}$ Therefore, it is highly desirable to develop a reproducible and standardized DOM isolation method that provides representative fractions, enabling large-scale studies of DOM while minimizing the inconsistencies among laboratories. $^{15}$

Suitable DOM isolation methods encompass reverse osmosis/electrodialysis (RO/ED) and ultrafiltration, both of which isolate DOM through membrane passage with physical pressure, which may also concentrate salts. ${ }^{16-19}$ Solid phase

Received: November 27, 2015

Accepted: May 13, 2016

Published: May 13, 2016 
extraction (SPE) has become a widely applied method for DOM isolation, ${ }^{10,20}$ and employs sample-, sorbent-, and solvent-dependent interactions to temporarily retain DOM, which is subsequently eluted in commonly concentrated solutions. To date, two main SPE methods for DOM isolation are commonly used: simultaneous enrichment of a wide range of DOM compounds by a single sorbent and stepwise selective fractionation of DOM using different sorbents. ${ }^{20-28}$ Because of its ease of operation and the limited diversity of the interactions involved, the first category has been the most widely used SPE method for DOM isolation.

Since the 1980s, scientists have investigated different types of SPE sorbents to improve DOC recovery. ${ }^{20}$ The classical XAD and improved DAX resins were the first-generation sorbents for DOM isolation, which enabled a recovery of hydrophobic acids in the range of $19 \%-90 \% .^{20-22}$ These sorbents have been supplemented by the second generation of silica-based sorbents, as a result of extensive labor and commercial availability. ${ }^{18,19,25}$ More recently, polymer-based sorbents have been widely utilized, because of their stability over wide $\mathrm{pH}$ ranges and simple extraction procedures. In particular, the sorbent of functionalized styrene divinylbenzene polymer ${ }^{28,29}$ (PPL) capable of extracting hydrophobic and certain polar compounds such as phenols, showed both appreciable DOM recovery and adequate depiction of the intrinsic DOM molecular diversity inherent to specific sources such as river, ground, lake, and seawater. ${ }^{29}$ In comparison with classical $\mathrm{XAD}-2$ resins, which are also styrene divinylbenzene polymers polymers, contemporary PPL resin features a larger specific surface area $\left(600 \mathrm{~m}^{2} / \mathrm{g}\right.$ versus $\left.300 \mathrm{~m}^{2} / \mathrm{g}\right)$, and proprietary functionalization for the improved retention of polar compounds such as phenols. Unlike the silica-based sorbent $\mathrm{C} 18$ and classical XAD-8 resin, PPL resin isolated representative DOM components with an abundance of aliphatic groups, and it was recommended for DOM extraction from natural waters. ${ }^{30}$ Furthermore, in contrast to DOM isolated by means of a reverse osmosis/electrodialysis (RO/ED) process and SPE with XAD sorbents, PPL-based SPE allowed the isolation of marine DOM with beneficial properties for both high-field Fourier transform ion cyclotron resonance mass spectrometry (FTICR MS) and nuclear magnetic resonance (NMR) spectroscopy detection, while showing appreciable DOC recovery. ${ }^{13,31}$

Despite approval of its use for DOM isolation and the critical dependence of all science developed from isolated polydisperse SPE-DOM, the DOM isolation parameters of SPE with PPL sorbent have not yet been systematically investigated. In this study, Suwannee River water was chosen because of its widespread utilization in many previous studies, limited interference from inorganic constituents and its availability at higher DOM concentration than other natural waters. The objective of this study was to develop an optimized SPE method for DOM isolation with PPL cartridges, to define standardized DOM isolation and analysis conditions for different DOM sources and laboratories. The influence of critical SPE variables such as loading mass, concentration, flow rate and up-scaling on DOM recovery, composition, and structure were systematically investigated in eluates, permeates, and wash liquids (Figure 1) by means of DOC analysis, ultrahigh-resolution FTICR mass spectrometry, and NMR spectroscopy. The latter two, information-rich detection methods provide the most direct relationships between the acquired data and molecular parameters available for DOM

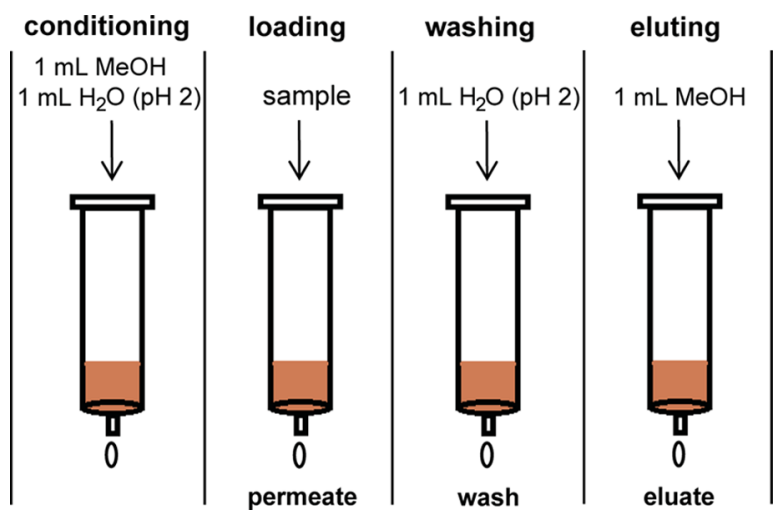

Figure 1. Scheme of the solid phase extraction of Suwannee River dissolved organic matter (SR DOM) with composition of investigated samples (100 mg PPL cartridges used).

characterization to date. ${ }^{1,11,13}$ Moreover, the SPE/PPL extract was compared with the authentic Suwannee River water (Suwwater) and the RO isolate from the International Humic Substances Society (IHSS SR natural organic matter reference, 2R101N, Suw-RO).

\section{EXPERIMENTAL SECTION}

Sample Preparation. Suwannee River water was collected in May 2012 from the headwaters of the Suwannee River $\left(30^{\circ} 48^{\prime} 14^{\prime \prime} \mathrm{N}, 82^{\circ} 25^{\prime} 03^{\prime \prime} \mathrm{W}\right)$ as it flows out from the Okefenokee Swamp, as described by Green et al. ${ }^{32}$ After sampling, the water was immediately filtered with $0.47 \mu \mathrm{m} \mathrm{GF} /$ $\mathrm{F}$ glass fiber (Whatman, precombusted at $450{ }^{\circ} \mathrm{C}$ ) and stored at $4{ }^{\circ} \mathrm{C}$ in darkness, using acid-washed polyethylene bottles. These samples were then transported in an air atmosphere at ambient temperature to Germany $(\sim 20 \mathrm{~h})$, and consecutively stored for several months in the refrigerator at $4{ }^{\circ} \mathrm{C}$. In the laboratory, this water was acidified to $\mathrm{pH} 2$ with $\mathrm{HCl}$ and subjected to commonly used $100 \mathrm{mg}$ cartridges with PPL sorbent (Agilent Bond Elut PPL; in the case of up-scaling, the cartridge size ranged from $100 \mathrm{mg}$ to $5 \mathrm{~g}$; cf. text). Blanks were used with acidified Milli- $\mathrm{Q}$ water $(\mathrm{HCl}, \mathrm{pH} 2)$. The SPE procedure was performed in triplicate according to Dittmar et al. $^{29}$ Samples were loaded on the cartridges in Teflon reservoirs $(60 \mathrm{~mL})$ connected by Luer adaptors at fixed flow rates with a peristaltic pump. After loading the samples, cartridges were rinsed with $1 \mathrm{~mL}$ of $\mathrm{pH} 2$ water (at the same ratio for upscaling experiments). After the washing step, the cartridges were dried with nitrogen gas for $10 \mathrm{~min}$ and were then eluted with $1 \mathrm{~mL}$ of methanol (at the same ratio for up-scaling experiments). The samples collected in the loading and washing steps and the final eluting steps were termed permeates, wash liquids, and eluates, respectively (see Figure 1). Following SPE, the permeates and wash samples were kept at $-4{ }^{\circ} \mathrm{C}$ in darkness and the methanolic eluates were kept at $-25^{\circ} \mathrm{C}$ prior to further analysis. ${ }^{33}$ FTMS analysis of the DOM solutions was performed immediately after sample workup; the DOM used for NMR characterization was kept under dry conditions at $-25{ }^{\circ} \mathrm{C}$ until analysis. The ${ }^{1} \mathrm{H}$ NMR spectra did not change visibly after the $\mathrm{CD}_{3} \mathrm{OD}$ solutions had been stored for several months at $-25{ }^{\circ} \mathrm{C}$ in darkness.

DOC Measurement. DOC concentrations were determined by high-temperature catalytic oxidation using a Shimadzu TOC-VCPN analyzer, according to Flerus et al. ${ }^{34}$ Samples $(500 \mu \mathrm{L}$ water solutions for the permeate and wash 

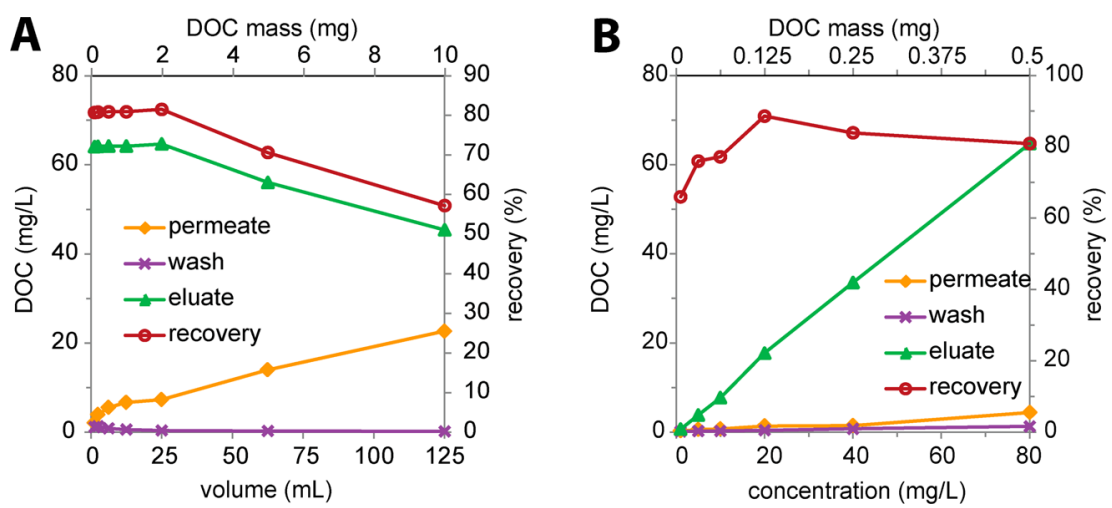

Figure 2. Values and recoveries of dissolved organic carbon (DOC) from Suwannee River SPE-DOM using 100 mg PPL cartridges with flow rate of $0.5 \mathrm{~mL} / \mathrm{min}$ : (A) effect of loading volume at fixed DOC concentration $(80 \mathrm{mg} / \mathrm{L})$; and (B) effect of the DOC concentration at fixed loading volume $(6.25 \mathrm{~mL})$. The DOC values of the permeates, wash liquids and eluates are shown on the left $y$-axis, and the DOC recovery is presented on the right $y$-axis. The recovery was calculated according to the formulas $100 \% \times(\mathrm{DOC}$ of eluate $) /($ original DOC $)$.

liquids, and $100 \mu \mathrm{L}$ for the eluates) were evaporated and redissolved in $1 \mathrm{~mL}$ of ultrapure water for analysis.

FTICR MS Analysis. High-field FTICR mass spectra were acquired using a $12 \mathrm{~T}$ Bruker Solarix mass spectrometer (Bruker Daltonics, Bremen, Germany) and an Apollo II electrospray ionization (ESI) source in negative ionization mode. Samples were diluted in methanol to a concentration of $\sim 5 \mu \mathrm{g} / \mathrm{mL}$, and then were injected into an electrospray source at a flow rate of $120 \mu \mathrm{L} / \mathrm{h}$ with a nebulizer gas pressure of 138 $\mathrm{kPa}$ and a drying gas pressure of $103 \mathrm{kPa}$. Spectra were first externally calibrated based on clusters of arginine in methanol (5 $\mu \mathrm{g} / \mathrm{mL})$, and internal calibration was systematically performed in the presence of natural organic matter, reaching accuracy values lower than $500 \mathrm{ppb}$. The spectra were acquired with a time domain of four megawords over a mass range of $\mathrm{m}$ / $z$ 150-1000 amu, and 500 scans were accumulated for each mass spectrum. Elemental formulas were calculated for each peak in a batch mode by using software developed in-house. ${ }^{35}$

NMR Analysis. All ${ }^{1} \mathrm{H}$ NMR spectra were acquired with a Bruker Avance III 500 spectrometer $\left(B_{0}=11.7 \mathrm{~T}\right)$ at $283 \mathrm{~K}$ from redissolved solids in $\mathrm{CD}_{3} \mathrm{OD}\left(99.95 \%{ }^{2} \mathrm{H}\right.$; Merck) with Bruker standard pulse sequences using 2-2.5 mm Bruker MATCH tubes. The reference ${ }^{1} \mathrm{H}$ NMR chemical shift of $\mathrm{HD}_{2} \mathrm{COD}$ was $3.3 \mathrm{ppm} .{ }^{1} \mathrm{H}$ NMR spectra were recorded under solvent suppression with presaturation and $1 \mathrm{~ms}$ spin-lock (noesypr1d), $5 \mathrm{~s}$ acquisition time, $5 \mathrm{~s}$ relaxation delay (d1), typically 1024 scans, and $1 \mathrm{~Hz}$ exponential line broadening. ${ }^{1} \mathrm{H}$ NMR section integrals were obtained by using the software AMIX at $0.01 \mathrm{ppm}$ resolution, with exclusions of $\mathrm{HDO}$ and $\mathrm{HD}_{2} \mathrm{COD}$ NMR resonances.

Hierarchical Clustering. The intensities of the peaks measured by FTICR MS were logarithmically transformed (prior to transformation, zeros were substituted by ones) and the R package "pvclust" was used to apply Hierarchical Clustering with Multiscale Bootstrap Resampling. Clustering of the samples was based on the Euclidean distance and Ward's linkage, with au/bp confidence levels (\%) provided (where au is denoted as the approximately unbiased $p$-value (given in red in the figure) and $b p$ is the bootstrap probability value). Hierarchical clustering among Suw-water, Suw-RO, and SPE/ PPL eluate was performed on Hierarchical Clustering Explorer due to the limited number of samples.

\section{RESULTS AND DISCUSSION}

Effect of Loading Mass. Although the effect of loading mass on the SPE extraction selectivity of DOM is significant, no systematic evaluation has been performed so far. The widely applied SPE method for DOM isolation developed by Dittmar et al. provided the advisible volume and amount of seawater DOM on $1 \mathrm{~g}$ PPL cartridges, ${ }^{29}$ but no detailed experiments about appropriate conditions for SPE of freshwater DOM have been performed to date. Minor et al. loaded $7.2 \mathrm{mg}$ of Lake Superior DOM (freshwater) and $4.16 \mathrm{mg}$ of Lester River Mouth DOM (freshwater) on $500 \mathrm{mg}$ PPL cartridges. They obtained large variability in DOC recovery $(31 \% \pm 3 \%$ and $57 \% \pm 6 \%$, respectively), ${ }^{27}$ which might be attributed to the compositional or structural variance of DOM or effects of overloading. The effect of loading mass in this study was evaluated in the following three ways: (1) at identical DOC concentration with different volumes, (2) at the same volume with different concentrations, and (3) at equal mass with different concentrations and volumes. First, at the original

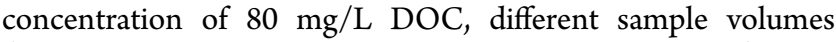
(1.25-125 mL, corresponding to $0.1-10 \mathrm{mg}$ of DOC) were loaded on $100 \mathrm{mg}$ PPL cartridges, and the DOC recovery was followed (Figure 2A). Here, the DOC mass of the eluates increased linearly, with loading volumes ranging from $1.25 \mathrm{~mL}$ to $25 \mathrm{~mL}$. However, further increases in the volume decreased the DOC recovery. This trend was quite different from that of a classical breakthrough curve, which is independent of loading volumes after the breakthrough is reached. ${ }^{36}$ This disparity resulted mostly from the heterogeneity of DOM, which covered a wide range of compounds, from polar to nonpolar characteristics. The interactions among the polydisperse and heterogeneous mixture of DOM molecules and the PPL sorbent, which occurred during the loading step, were much more diverse than those defining the classical breakthrough curves originating from single compounds or certain groups of related compounds. It is conceivable that DOC is fractionated progressively during loading onto a PPL sorbent with the least strongly adsorbed polar molecules gradually being replaced on the PPL as more sample is loaded onto the PPL. The DOC recovery of the eluates increased slightly up to a loading volume of $25 \mathrm{~mL}$, and then it decreased. The DOC recovery of the permeates showed the opposite trend, whereas that of the wash liquids remained quite low. DOC blanks measured from each step were found below the detection limit of the instrument, 

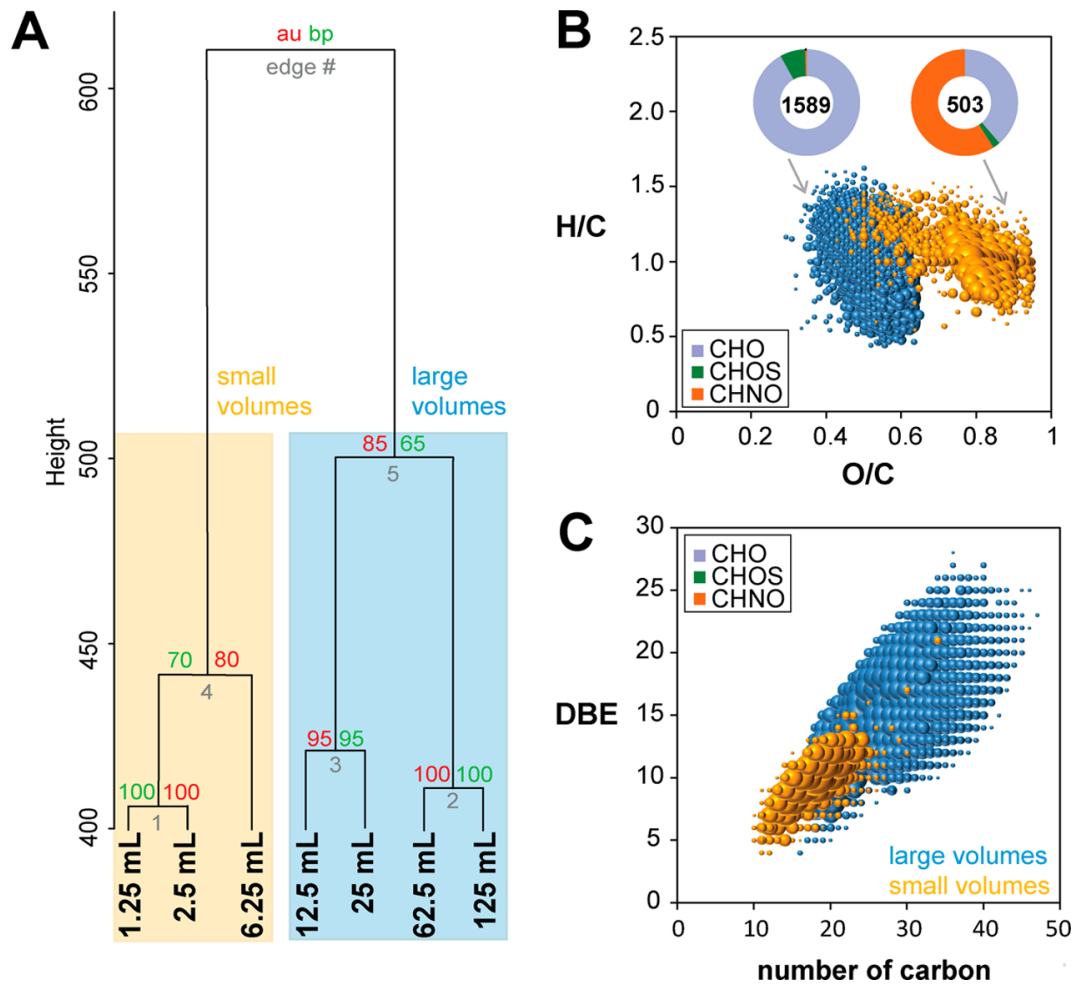

Figure 3. (A) Cluster dendrogram of eluates at different loading volumes ( $\mathrm{DOC}=80 \mathrm{mg} / \mathrm{L}$, flow rate $=0.5 \mathrm{~mL} / \mathrm{min}, 100 \mathrm{mg} \mathrm{PPL} \mathrm{cartridges}$ ), based on peak amplitudes from FTICR MS measurement. Boxes are drawn around the clusters with $\geq 80 \%$ au; (B) Van Krevelen diagram of the masses uniquely detected at large and small loading volumes $(<10 \mathrm{~mL}$; shown in orange). The two pie charts indicate the number of assigned molecular formulas; (C) Double bond equivalents (DBE) vs number of carbon atoms. Identical color code corresponds to the shading in the cluster dendrogram shown in panel A. The bubble size corresponds to the intensities obtained by FTICR MS.

and no relevant mass peaks except random noise peaks were observed in FTICR mass spectra and associated van Krevelen diagrams (data not shown).

Depending on the loading volume, the negative electrospray ionization FTICR mass spectra of the eluates provided two distinct sets of DOM molecules, demonstrating the dependence of the eluate DOM molecular composition on the DOM/PPL mass ratio employed in SPE (Figure 3). At larger loading volumes, certain constituents of highly oxygenated molecules $(\mathrm{O} / \mathrm{C}=0.5-0.97)$ were gradually replaced by less-oxygenated ones $(\mathrm{O} / \mathrm{C}=0.4-0.6)$, which also showed higher DBE values, indicative of higher molecular unsaturation (Figures $3 \mathrm{~B}$ and 3C). ${ }^{1} \mathrm{H}$ NMR spectra showed increased aliphaticity $\left(\delta_{\mathrm{H}}=0.5-\right.$ $1.9 \mathrm{ppm})$ at the expense of carboxylic-rich aromatic molecules (CRAM) $\left(\delta_{\mathrm{H}}=1.9-3.1 \mathrm{ppm}\right)$, and carbohydrate and methoxy groups $\left(\delta_{\mathrm{H}}=3.4-4.9 \mathrm{ppm}\right)^{12,13}$ at higher loading volumes (Figure 4$)$. These changes in molecular composition were in agreement with the decrease in DOC of eluates at higher loading volumes, as shown above, and indicated progressive displacement of weakly bonded DOC constituents such as carbohydrates and functionalized aliphatics by less-oxidized (i.e., oxygen-deficient) DOM molecules of higher aliphatic and aromatic content. Concomitant molecular changes in the fractions of permeates and wash liquids are shown in Figures S1, S2, and S3 in the Supporting Information. At small loading volumes, compounds with high $\mathrm{O} / \mathrm{C}$ ratios $(0.6-0.97)$ as well as small molecular weight (mainly $180-400 \mathrm{~m} / z$ ) were detected in the permeates, indicating that these molecules had poor retention on the cartridges (Figure S1). With increasing loading volumes, compounds with lower $\mathrm{O} / \mathrm{C}$ ratios and higher molecular weight could also be found in the

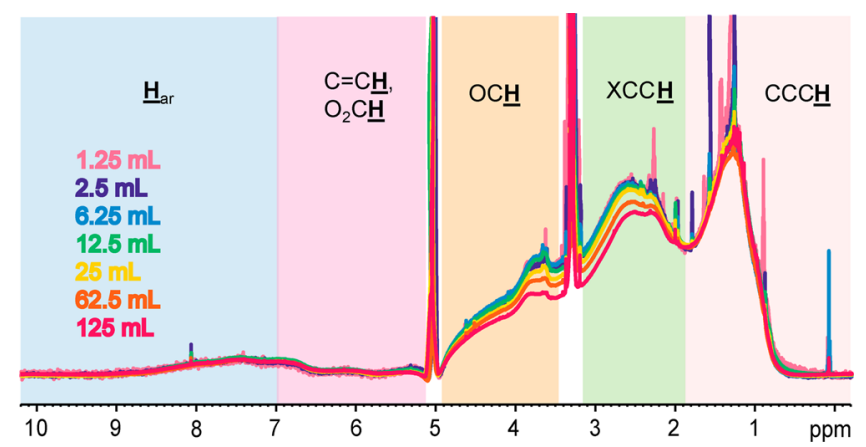

Figure 4. ${ }^{1} \mathrm{H}$ NMR spectra $\left(500 \mathrm{MHz}, \mathrm{CD}_{3} \mathrm{OD}\right)$ of the eluates obtained at different loading volumes $(\mathrm{DOC}=80 \mathrm{mg} / \mathrm{L}$, flow rate $=$ $0.5 \mathrm{~mL} / \mathrm{min}, 100 \mathrm{mg}$ PPL cartridges). The spectra were normalized to the identical total NMR integral.

permeates. Interestingly, the compounds found in permeates at large volumes showed classical DOM-like ${ }^{1} \mathrm{H}$ NMR spectra with rather contiguous and broad NMR resonances, representative of aliphatics, CRAM, carbohydrates, olefins, and aromatics, whereas those obtained from small-volume experiments exhibited mainly aliphatic peaks with superimposed small NMR resonances (Figure S2A). Similar trends were observed in the wash liquids, but with larger proportions of aliphatics and CRAM observed in the ${ }^{1} \mathrm{H}$ NMR spectra at large loading volumes. Taking into account the DOC recoveries and relative uniformity of the DOM compositions, $6.25 \mathrm{~mL}$ of SR DOM (0.5 mg of DOC mass) was chosen as the optimal loading volume and used for further experiments. At this volume, the mass ratio employed for DOM and PPL sorbent 

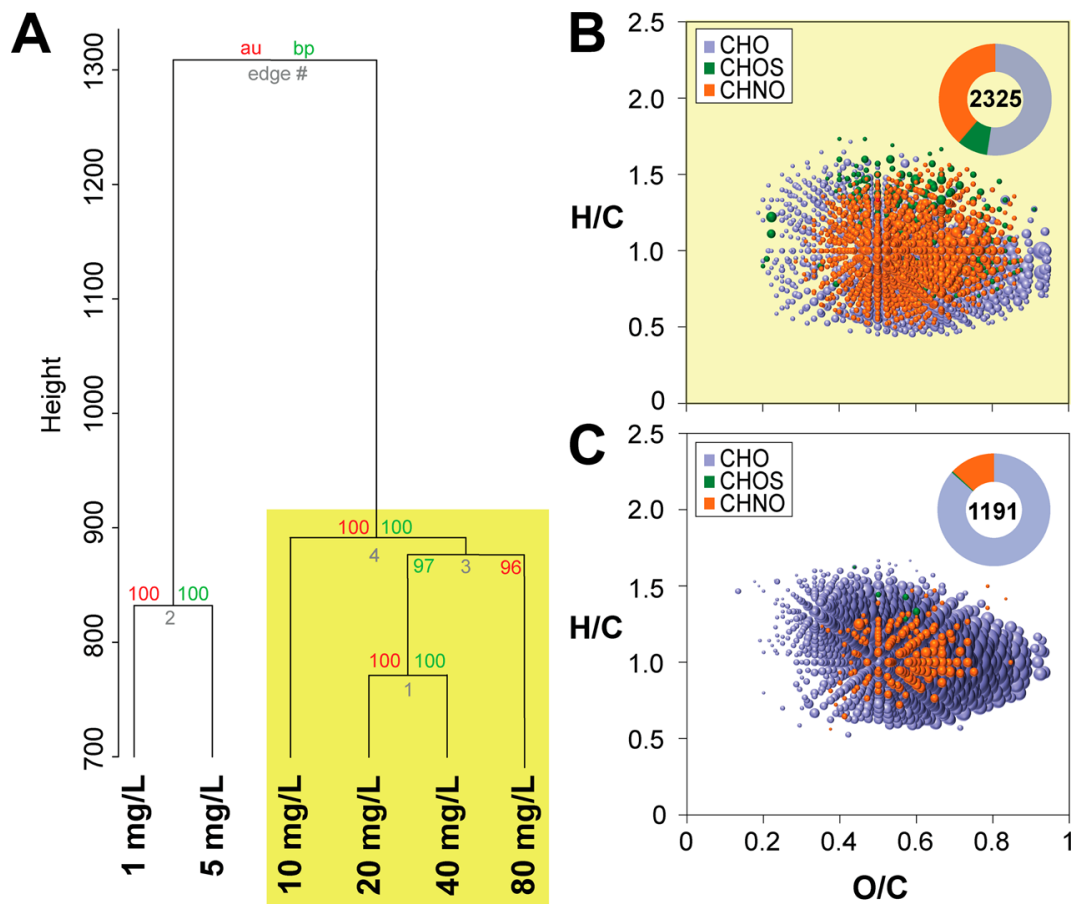

Figure 5. (A) Cluster dendrogram of eluates at different concentrations (volume $=6.25 \mathrm{~mL}$, flow rate $=0.5 \mathrm{~mL} / \mathrm{min}, 100 \mathrm{mg}$ PPL cartridges), based on measured intensities from FTICR MS measurements. Boxes are drawn around the clusters with au $\geq 96 \%$; (B) Van Krevelen diagrams of the masses uniquely detected at large concentrations (DOC $\geq 10 \mathrm{mg} / \mathrm{L}$ ) (see the yellow highlighted section in the cluster dengrogram shown in panel A); (C) detected at all concentrations. Pie charts indicate the number of assigned formulas. The bubble size corresponds to the intensities obtained by FTICR MS.

Table 1. ${ }^{1} \mathrm{H}$ NMR Section Integrals for the Key Structures of Eluates Obtained under Different Different Loading Concentrations (Volume $=6.25 \mathrm{~mL}$, Flow Rate $=0.5 \mathrm{~mL} / \mathrm{min} ; 100 \mathrm{mg}$ PPL Cartridges) and Different Up-Scaling $($ Concentration $=20 \mathrm{mg} / \mathrm{L} ;$ Volume $=6.25 \mathrm{~mL}$; Flow Rate $=0.5 \mathrm{~mL} / \mathrm{min}$ )

\begin{tabular}{|c|c|c|c|c|c|}
\hline & $\delta\left({ }^{1} \mathrm{H}\right)=9.5-7.0 \mathrm{ppm}$ & $\delta\left({ }^{1} \mathrm{H}\right)=7.0-5.3 \mathrm{ppm}$ & $\delta\left({ }^{1} \mathrm{H}\right)=4.9-3.6 \mathrm{ppm}$ & $\delta\left({ }^{1} \mathrm{H}\right)=3.1-1.9 \mathrm{ppm}$ & $\delta\left({ }^{1} \mathrm{H}\right)=1.9-0.5 \mathrm{ppm}$ \\
\hline key structure(s) & $\underline{\mathrm{H}}_{\mathrm{ar}}$ & $\underline{\mathrm{HC}}=\mathrm{C}, \mathrm{HCO}_{2}$ & $\underline{\mathrm{H}} \mathrm{CO}$ & $\underline{\mathrm{HCCX}}^{a}$ & $\underline{\mathrm{HCCC}}$ \\
\hline \multicolumn{6}{|l|}{ concentration $(\mathrm{mg} / \mathrm{L})$} \\
\hline 1 & 5.9 & 1.3 & 5.3 & 32.5 & 55.0 \\
\hline 5 & 5.5 & 1.1 & 4.7 & 35.1 & 53.6 \\
\hline 10 & 3.5 & 0.9 & 19.1 & 43.5 & 33.0 \\
\hline 20 & 3.8 & 0.4 & 17.9 & 41.4 & 36.5 \\
\hline 40 & 4.3 & 0.4 & 17.5 & 41.4 & 36.4 \\
\hline 80 & 4.5 & 0.2 & 17.3 & 41.5 & 36.4 \\
\hline \multicolumn{6}{|l|}{ up-scaling (mg) } \\
\hline 100 & 3.8 & 0.4 & 18.0 & 41.3 & 36.5 \\
\hline 200 & 3.7 & 0.5 & 18.0 & 41.4 & 36.4 \\
\hline 500 & 3.7 & 0.5 & 18.0 & 41.3 & 36.5 \\
\hline 1000 & 3.7 & 0.5 & 22.4 & 40.9 & 32.5 \\
\hline 5000 & 3.7 & 0.5 & 22.5 & 41.0 & 32.3 \\
\hline
\end{tabular}

was 1:200. At $\sim 50 \%$ carbon content of DOM, the optimum mass ratio of DOC and PPL sorbent accounted for a ratio of $1: 100$, which was in near accordance with the ratio of $1 \%-5 \%$ proposed for the retention of more uniform mixtures. ${ }^{36}$

As the sample volume and DOC concentration might influence the SPE extraction selectivity, additional experiments were performed at the same DOC mass $(0.5 \mathrm{mg})$ but with different loading volumes and DOC concentrations. Here, only marginal variance in the DOC recovery of permeates, wash liquids, and eluates was detected (Figure S4A). A rather congruent presence of aliphatic NMR resonances was observed in the permeates and wash liquids (Figure S2B and S3B). Near $89 \%$ common mass peaks were observed in all six FTICR mass spectra for the eluates (Figure S5A), in line with the distinctive congruence observed in the ${ }^{1} \mathrm{H}$ NMR spectra (Figure S6A). This indicated near uniform molecular compositions and structures at identical DOC loading mass, independent of the volumes and concentrations used for SPE. This finding is important for the practical application in specific ecosystems in which DOC quality and concentrations may vary substantially. $^{37}$ 
Hence, the results above showed that DOC recovery and structures were quite uniform up to a DOC/PPL mass ratio of $1: 200$. We then have investigated the effects of variable DOC concentration at a fixed volume $(6.25 \mathrm{~mL})$ of SR DOM solution. The highest DOC recovery $(\sim 89 \%)$ was obtained at a concentration of $20 \mathrm{mg} / \mathrm{L}$, corresponding to a DOC/PPL mass ratio of 1:800 (Figure 2B). The FTMS-derived cluster dendrogram (Figure 5A) clearly showed two clusters at a 96\% significance level: the eluate molecules obtained at larger concentrations were statistically different from those obtained at small concentrations. A large number of $\mathrm{CHNO}$ compounds were exclusively detected at larger concentrations (Figure 5B). The common eluate molecules that were present in all six different concentrations were less numerous than those found at larger concentrations, and they contained only $\sim 20 \% \mathrm{CHNO}$ compounds (Figure 5C). ${ }^{1} \mathrm{H}$ NMR section integrals showed a rather congruent abundance of key substructures at higher concentrations $(\geq 20 \mathrm{mg} / \mathrm{L})$, whereas a very considerable increase of aliphatic units was observed at low concentrations at the expense of both functionalized aliphatics (XCC $\underline{\mathrm{H}}$ ) and oxygenated aliphatics ( $\mathrm{OC} \underline{\mathbf{H}})$ (see Table 1$)$. Superimposed low amplitude lipid-derived NMR resonances were observed in the permeates and wash liquids (Figures S2C and S3C). Thus, an optimal DOC concentration of $20 \mathrm{mg} / \mathrm{L}$ was chosen for further experiments. However, in natural environments, the concentration of DOM varied greatly, typically ranging from 5 to 20 $\mathrm{mg} / \mathrm{L}$ in freshwater, with the exception of Suwannee River water $(\sim 84 \mathrm{mg} / \mathrm{L}$ at the time of sampling) and other peatdraining waters at $\sim 80 \mathrm{mg} / \mathrm{L} .^{27,38,39}$ Based on our results, dilution is suggested in the case of highly concentrated DOM such as sewage, and the use of larger volumes of freshwater is recommended at low DOC content within the capacity of the cartridge for meaningful SPE-based isolation of DOC. Samples with high contents of suspended solids and high ionic strength require centrifugation after filtration and dilution, respectively.

Effect of Flow Rate. A proper flow rate is important for desirable DOC recovery during the SPE process, especially during loading and eluting steps. While a fast flow rate diminishes DOC recovery, as a result of insufficient absorption of analytes on sorbents, a flow rate that is too slow reduces the overall productivity. ${ }^{36}$ In our study, different flow rates were chosen in the range of $0.5-5 \mathrm{~mL} / \mathrm{min}$. Here, variable flow rates had no significant effect on DOC recovery (Figure S4B in the Supporting Information), FTICR mass spectra (Figure S5B in the Supporting Information) and NMR spectra (Figures S2D, $\mathrm{S} 3 \mathrm{D}$, and $\mathrm{S} 6 \mathrm{~B}$ in the Supporting Information). These findings are encouraging as being independent of DOC recovery, composition, and structure, with respect to the flow rate, and will facilitate a meaningful DOM isolation by means of SPE/ PPL under demanding field conditions. Hence, a flow rate of $0.5 \mathrm{~mL} / \mathrm{min}(2-3 \mathrm{~s}$ per drop) was kept for all further experiments.

Effect of Up-Scaling. The up-scaling of SPE conducted under the optimized conditions $(20 \mathrm{mg} / \mathrm{L}$ DOC and $0.5 \mathrm{~mL} /$ min flow rate) with cartridges of different sizes, ranging from $100 \mathrm{mg}$ to $5 \mathrm{~g}$ of PPL sorbent material (i.e., 100, 200, 500, $1000,5000 \mathrm{mg}$; see Table 1), resulted in a near uniform DOC recovery $(87 \%-89 \%$; Figure S4C). The NMR spectra of the permeates and wash liquids showed mainly aliphatics and rather sharp resonances of oxygenated carboxylic acids (see Figures S2E and S3E). Approximately $94 \%$ common masses were present in the FTICR mass spectra of all five eluates (see Figure $\mathrm{S} 5 \mathrm{C}$ ), demonstrating the high reproducibility of the SPE procedure. In contrast, ${ }^{1} \mathrm{H}$ NMR section integrals (Table 1) already suggested a clear division of the five SPE-DOM eluates into (1) a uniform group of small cartridges (100-500 mg) with higher aliphaticity and lower content of $\mathrm{OCH}$ groups (Table 1) and a uniform group of large cartridges ( $1 \mathrm{~g}$ and $5 \mathrm{~g}$ ) with the opposite distribution. Here, methoxy groups $\left(\mathrm{OCH}_{3}\right.$; $\delta_{\mathrm{H}}=3.4-4.0 \mathrm{ppm}$ ) showed higher abundance in the case of larger PPL cartridges used (Figure S6C). These newly observed compounds were likely methyl esters, which might have been formed at the low $\mathrm{pH}$ associated with the increased residence time during SPE at larger scaleup. The exposure of humic substances to high concentrations of methanol and traces (catalytic amounts) of strong acid has been found to initiate self-esterification. ${ }^{33,40}$

Comparison of Original Suwannee River Water, IHSS Reverse Osmosis Isolate, and SPE Extract. In order to assess the relationships between three well-available types of Suwannee river organic matter, ${ }^{1} \mathrm{H}$ NMR spectra were recorded from the dried and redissolved authentic Suw-water, Suw-RO [IHSS reference sample of Suwannee River NOM (2R101N)], and SPE/PPL used in our study, all of which were isolated at the same time in May 2012. ${ }^{32}$ To ensure maximum compatibility and to avoid distortions from differential solubility, ${ }^{41}$ these organic matter isolates were dissolved in mixtures of $\mathrm{CD}_{3} \mathrm{OD}$ and $\mathrm{D}_{2} \mathrm{O}(50 / 50, \mathrm{v} / \mathrm{v})$ such that the ${ }^{1} \mathrm{H}$ NMR spectra were acquired under identical conditions.

In agreement with previous reports, ${ }^{10,31,42}$ Suw-RO showed a slightly higher recovery $(94.2 \%)^{32}$ than the PPL extract (89\%). Despite the slight variation in DOC recovery, a satisfactory overall congruence of all three Suwannee River organic matter isolates was observed, with respect to NMR line shape distribution (see Figure S7 in the Supporting Information) and the ${ }^{1} \mathrm{H}$ NMR section integrals (Figure S8 in the Supporting Information), and difference spectra were acquired to reveal the dissimilarities among these materials (Figure S7). Here, the SPE/PPL extract showed a relatively higher contribution of aliphatic NMR resonances $\left(\delta_{\mathrm{H}}=0.5-2.2 \mathrm{ppm}\right)$ than Suw-water and Suw-RO, albeit at, however, variable selectivity (Figure S7). A rather sharp peak at $\delta_{\mathrm{H}} \approx 1.22 \mathrm{ppm}$ may consist of contributions from long chain aliphatic compounds in the SPE eluate, which were less abundant in the two other isolates. This putative selectivity of the PPL sorbent toward hydrophobic and low-molecular-weight molecules in DOM has been previously reported. $^{30,42}$ Comparing Suw-water with Suw-RO, aliphatics and olefins were depleted in Suw-RO, whereas CRAM and, in particular, carbohydrates and some methoxy groups $\left(\mathrm{OCH}_{3}\right)$ were more abundant in Suw-RO. Interestingly, common aromatic molecules $\left(\delta_{\mathrm{H}}=6.7-7.8 \mathrm{ppm}\right)$ were also more abundant in Suw-RO than in Suw-water, with no obvious discrimination of electron-donating $\left(\delta_{\mathrm{H}}<7 \mathrm{ppm}\right)$, electronneutral $\left(\delta_{\mathrm{H}}=7.0-7.3 \mathrm{ppm}\right)$, and electron-withdrawing $\left(\delta_{\mathrm{H}}>\right.$ 7.3 ppm) substituents. ${ }^{43}$ The abundance of certain small molecules, such as acetic acid $\left(\delta_{\mathrm{H}} \approx 1.89 \mathrm{ppm}\right.$; noticeable in both Suw-water and Suw-RO) and formate $\left(\delta_{\mathrm{H}} \approx 8.3 \mathrm{ppm}\right.$, depending on intrinsic $\mathrm{pH}$; abundant in both Suw-water and Suw-RO), as well as other sharp NMR resonances, was samplespecific, but not decisive in the assessment of sample properties. However, tiny NMR resonances in the carbohydrate region $\left(\delta_{\mathrm{H}}\right.$ $=3.5-4.2 \mathrm{ppm}$ ) were distinctively different; in particular, SuwRO exhibited patterns indicative of carbohydrates, whereas the SPE/PPL sample showed a remarkable small contribution of methoxy groups (shaded box in Figure S7). 
Hierarchical cluster analysis (HCA) grouped original Suwwater together with Suw-RO (Figure S8), suggesting that Suw$\mathrm{RO}$ was more representative of the original water than the SPE/PPL extract, in accordance with previous reports. However, recognition of residual chemical exchange in our ${ }^{1} \mathrm{H}$ NMR spectra (Figure S7) placed the SPE eluate rather close to the Suw-water composition. The common discrimination of PPL-based SPE against carbohydrates does not overly apply in this study, because of the limited abundance of carbohydrates in Suw-water. ${ }^{32}$

The remarkably large difference in the relative NMR resonance amplitude in the vicinity of the residual HDO resonance at $\delta_{\mathrm{H}} \approx 5.0 \mathrm{ppm}$ was initially surprising, and these effects remained under several different NMR acquisition conditions, including acquisition in pure $\mathrm{CD}_{3} \mathrm{OD}$ solution. We presently attribute this phenomenon to the $800 \mathrm{MHz}$ high-Q cryogenic probehead with inverse detection (i.e., the ${ }^{1} \mathrm{H}$ NMR coil is close to the sample) at exceptional sensitivity and frequency spread (chemical shift differences $\Delta \delta_{i j}$ between exchanging nuclei $i$ and $j$ show a large spread in frequency $\left.\Delta \nu_{i j}\right)$, in which residual chemical exchange between capable functional groups rather than differential abundance of olefins may primarily affect this region of chemical shift. Hence, we do not attribute high significance to the NMR resonance amplitude variations at $\delta_{\mathrm{H}}=4.5-6.5 \mathrm{ppm}$ (observed in these three samples).

NMR section integrals provided the relative quantities of the key substructures (see Figure $\mathrm{S} 8$ in the Supporting Information) among the three samples: general (CCC $\underline{\mathrm{H}} ; \delta_{\mathrm{H}}$ $=0.5-1.95 \mathrm{ppm})$ and functionalized (XCC $\underline{\mathrm{H}}, \mathrm{X}=\mathrm{O} \gg N>S$; $\left.\delta_{\mathrm{H}}=1.95-3.1 \mathrm{ppm}\right)$ aliphatics contributed more than $70 \%$ of the total components, consistent with the previous DOM analyses. $^{12,44}$ General OCH units, such as carbohydrates, ethers, esters, and alcohols, accounted for $20 \%$, whereas aromatics accounted for $4 \%-5 \%$ and olefins accounted for $<2 \%$. As expected from the NMR difference spectra, the individual section integrals also varied between samples. Here, the SPE/PPL extract contained the highest percentage of pure aliphatics and lowest proportions of functionalized aliphatics, such as carboxyl-rich alicyclic molecules (CRAM) as well as OC $\underline{H}$ units. In contrast, Suw-RO was enriched in CRAM as well as carbohydrates and depleted of aliphatics. Alterations in olefin abundance were convoluted with effects of residual chemical exchange; however, it is likely that olefin abundance followed the order SPE/PPL < Suw-RO $\approx$ Suw-water. The abundance of aromatics was nearly equal in Suw-RO and SPE/ PPL extract and remarkably higher in Suw-RO than in Suwwater (see Figure S7).

The count of FTMS-derived assigned molecular formulas for the three samples followed the order Suw-RO > Suw-water > SPE/PPL, and $\sim 75 \%$ of shared masses among the three samples were observed (see Figure $S 9$ in the Supporting Information). Suw-RO showed the highest number of unique masses, whereas the SPE/PPL extract showed the lowest. The average molecular weight ranged in the order Suw-RO $>$ SPE/ PPL > Suw-water (Table 1), and the Suw-RO sample was the most distinct from the other two, based on elemental compositions, which was probably caused by the presence of high mass $(m / z>500)$ molecules of average $\mathrm{H} / \mathrm{C}$ ratio $(\mathrm{H} / \mathrm{C}$ $\approx 1.25)$. To put the FTMS-derived molecular compositions into perspective, the respective atomic ratios of Suw-RO were compared with the respective elemental analysis from the IHSS database (http://www.humicsubstances.org/elements.html).
With the exception of $\mathrm{N}$ - and S-containing molecules, which appeared attenuated in mass spectra, a very good concordance was observed (Table S1 in the Supporting Information). The small discrepancies observed likely resulted from ionization selectivity, ${ }^{45}$ which probably favored detection of aliphatic carboxylic acids with low $\mathrm{O} / \mathrm{C}$ ratios, thereby explaining the small gain in $\mathrm{H} / \mathrm{C}$ ratios and tiny decrease in $\mathrm{O} / \mathrm{C}$ ratios.

Noticeable discrepancies in $\mathrm{CHO}$ and $\mathrm{CHNO}$ compounds among the three samples plotted in van Krevelen diagrams were observed in mainly two regions (see Figure S10 in the Supporting Information). The first region was in the highly oxygenated area with $\mathrm{O} / \mathrm{C}$ ratios $>0.9$, for which fewer masses were found in the SPE/PPL extract. This was consistent with the results described above, namely, that molecules with high $\mathrm{O} / \mathrm{C}$ ratios could be detected in permeates and wash liquids. The second area was located in the more-saturated section of lipids $(\mathrm{O} / \mathrm{C}$ ratios $=0.2-0.3, \mathrm{H} / \mathrm{C}$ ratios $=1.2-1.6)$ where masses were depleted in the SPE/PPL extract. The loss of compounds in the first and second regions could be explained by their rather hydrophobic characteristics, which adhere strongly to the PPL sorbent. These results were in agreement with those of other authors, who reported that SPE discriminated against certain major groups: fatty acids with high $\mathrm{H} / \mathrm{C}$ and low $\mathrm{O} / \mathrm{C}$ ratios and tannin-like compounds. ${ }^{19}$ Also noteworthy was the presence of numerous oxygenated CHOS compounds at $\mathrm{H} / \mathrm{C} \approx 1.3$ and $\mathrm{O} / \mathrm{C}$ ratios of $\sim 0.6-0.9$ in Suw-RO and of hydrogen-deficient $\mathrm{CHOS}$ compounds at $\mathrm{H} /$ $\mathrm{C} \approx 0.6$ and $\mathrm{O} / \mathrm{C}$ ratios of $\sim 0.2-0.45$ in Suw-water. In addition, the main dissimilarity denoted in the mass-edited $\mathrm{H}$ / C ratios was obtained for Suw-RO, which showed abundant mass peaks at both low and high mass $(\mathrm{m} / z=150-250$ and 650-730). Overall, FTMS-based clustering analysis demonstrated that the SPE/PPL extract better resembled Suw-water than the Suw-RO sample (see Figure S10).

\section{CONCLUSIONS}

The styrene-divinylbenzene copolymer (PPL)-based solid phase extraction (SPE) of DOM relies on interactions between polydisperse organic molecules of considerable structural variance and a modified styrene divinylbenzene-type stationary phase; therefore, it is prone to chemical selectivity, depending on the extraction conditions, such as loading masses, concentration, and flow rate, as well as up-scaling. The combination of Fourier transform ion cyclotron resonance mass spectrometry (FTICR MS) and nuclear magnetic resonance (NMR) spectroscopy allowed the effects of these conditions on the molecular composition and structure of DOM to be monitored. A near-maximum DOC recovery of $89 \%$ was realized at a DOC concentration of $20 \mathrm{mg} / \mathrm{L}$ and flow rate of $0.5 \mathrm{~mL} / \mathrm{min}$ with a $\mathrm{DOC} /$ sorbent mass ratio of $1: 800$. High loading mass discriminated against highly oxygenated compounds, carboxylic-rich aromatic molecules (CRAM), carbohydrates, and methyl esters. No significant effect of flow rate was observed. The increased residence time of acidic, methanolic DOM solutions on PPL cartridges may lead to DOM self-esterification. Comparison of the SPE/PPL extract with the original water and an RO sample showed that the SPE/PPL extract was highly representative, in terms of DOM characteristics. This protocol for DOM isolation, based on SPE with PPL, allows for large-scale studies of DOM isolation while minimizing the potential inconsistencies between interlaboratory studies. 


\section{ASSOCIATED CONTENT}

\section{S Supporting Information}

The Supporting Information is available free of charge on the ACS Publications website at DOI: 10.1021/acs.analchem.5b04501.

Van Krevelen diagrams of permeates and wash liquids (Figure S1); ${ }^{1} \mathrm{H}$ NMR spectra of permeates (Figure S2) and wash liquids (Figure S3); DOC concentrations and recoveries under different SPE conditions (Figure S4); Van Krevelen diagrams and mass-edited $\mathrm{H} / \mathrm{C}$ ratios of common masses in FTICR mass spectra of all eluates obtained under different conditions (Figure S5); ${ }^{1} \mathrm{H}$ NMR spectra of eluates obtained under different conditions (Figure S6); ${ }^{1} \mathrm{H}$ NMR spectra of Suwannee river organic matter isolates (Figure S7); ${ }^{1} \mathrm{H}$ NMR section integrals for key substructures of the three Suwannee River organic matter isolates (Suwannee River water (Suw-water); IHSS reverse osmosis NOM (2R101N; Suw-RO); and SPE/PPL eluates) and a cluster dendrogram of the three samples obtained from ${ }^{1} \mathrm{H}$ NMR section integrals (Figure S8); Venn diagram of the number of assigned formulas of the three Suwannee River organic matter isolates (Figure S9); and mass peak counts, as computed from FTICR MS data for singly charged ions with nitrogen rule check and $500 \mathrm{ppb}$ tolerance (Table S1) (PDF)

\section{AUTHOR INFORMATION}

\section{Corresponding Author}

*Tel.: +49-89-3187-2834. Fax: +49-89-3187-2705. E-mail: hertkorn@helmholtz-muenchen.de.

\section{Notes}

The authors declare no competing financial interest.

\section{ACKNOWLEDGMENTS}

The authors are thankful to China Scholarship Council (CSC) for the financial support of $\mathrm{Yan} \mathrm{Li}$, and International Humic Substances Society (IHSS) for the financial support of Dr. Norbert Hertkorn during the Suwannnee River sampling campaign in May 2012. The authors thank Claudia Baurau (AWI) for the DOC measurements.

\section{REFERENCES}

(1) Hertkorn, N.; Ruecker, C.; Meringer, M.; Gugisch, R.; Frommberger, M.; Perdue, E. M.; Witt, M.; Schmitt-Kopplin, P. Anal. Bioanal. Chem. 2007, 389, 1311-1327.

(2) Bianchi, T. S. Proc. Natl. Acad. Sci. U. S. A. 2011, 108, 1947319481.

(3) Kujawinski, E. B. Annu. Rev. Mar. Sci. 2011, 3, 567-599.

(4) Kellerman, A. M.; Dittmar, T.; Kothawala, D. N.; Tranvik, L. J. Nat. Commun. 2014, 5, 3804.

(5) Ward, N. D.; Keil, R. G.; Medeiros, P. M.; Brito, D. C.; Cunha, A. C.; Dittmar, T.; Yager, P. L.; Krusche, A. V.; Richey, J. E. Nat. Geosci. 2013, 6, 530-533.

(6) Landa, M.; Cottrell, M. T.; Kirchman, D. L.; Kaiser, K.; Medeiros, P. M.; Tremblay, L.; Batailler, N.; Caparros, J.; Catala, P.; Escoubeyrou, K.; Oriol, L.; Blain, S.; Obernosterer, I. Environ. Microbiol. 2014, 16, 1668-1681.

(7) Asmala, E.; Autio, R.; Kaartokallio, H.; Stedmon, C. A.; Thomas, D. N. Aquat. Sci. 2014, 76, 451-463.

(8) Romano, S.; Dittmar, T.; Bondarev, V.; Weber, R. J.; Viant, M. R.; Schulz-Vogt, H. N. PLoS One 2014, 9, e96038.
(9) Nebbioso, A.; Piccolo, A. Anal. Bioanal. Chem. 2013, 405, 109124.

(10) Minor, E. C.; Swenson, M.; Mattson, B. M.; Oyler, A. R. Environ. Sci.: Processes Impacts 2014, 16, 2064-2079.

(11) Mopper, K.; Stubbins, A.; Ritchie, J. D.; Bialk, H. D.; Hatcher, P. G. Chem. Rev. 2007, 107, 419-442.

(12) Hertkorn, N.; Benner, R.; Frommberger, M.; Schmitt-Kopplin, P.; Witt, M.; Kaiser, K.; Kettrup, A.; Hedges, J. I. Geochim. Cosmochim. Acta 2006, 70, 2990-3010.

(13) Hertkorn, N.; Harir, M.; Koch, B. P.; Michalke, B.; SchmittKopplin, P. Biogeosciences 2013, 10, 1583-1624.

(14) Zhang, F.; Harir, M.; Moritz, F.; Zhang, J.; Witting, M.; Wu, Y.; Schmitt-Kopplin, P.; Fekete, A.; Gaspar, A.; Hertkorn, N. Water Res. 2014, 57, 280-294.

(15) Raterink, R.-J.; Lindenburg, P. W.; Vreeken, R. J.; Ramautar, R.; Hankemeier, T. TrAC, Trends Anal. Chem. 2014, 61, 157-167.

(16) Benner, R.; Pakulski, D.; McCarthy, M.; Hedges, J. I.; Hatcher, P. G. Science 1992, 255, 1561-1564.

(17) Koprivnjak, J.-F.; Pfromm, P. H.; Ingall, E.; Vetter, T. A.; Schmitt-Kopplin, P.; Hertkorn, N.; Frommberger, M.; Knicker, H.; Perdue, M. E. Geochim. Cosmochim. Acta 2009, 73, 4215-4231.

(18) Kruger, B. R.; Dalzell, B. J.; Minor, E. C. Aquat. Sci. 2011, 73, 405-417.

(19) Tfaily, M. M.; Hodgkins, S.; Podgorski, D. C.; Chanton, J. P.; Cooper, W. T. Anal. Bioanal. Chem. 2012, 404, 447-457.

(20) Thurman, E. M.; Malcolm, R. L. Environ. Sci. Technol. 1981, 15, 463-466.

(21) Perdue, E. M.; Ritchie, J. D. Dissolved Organic Matter in Freshwaters. In Surface and Ground Water Wesathering and Soils; Drever, J. I., Ed.; Holland, H. D., Turekian, K. K., Exec. Eds.; Treatise on Geochemistry, Vol. 5; Elsevier: Philadelphia, PA, 2003; pp 273318 (DOI: 10.1016/B0-08-043751-6/05080-5).

(22) Peuravuori, J.; Lehtonen, T.; Pihlaja, K. Anal. Chim. Acta 2002, 471, 219-226.

(23) Ratpukdi, T.; Rice, J. A.; Chilom, G.; Bezbaruah, A.; Khan, E. Water Environ. Res. 2009, 81, 2299-2308.

(24) Rosario-Ortiz, F. L.; Kozawa, K.; Al-Samarrai, H. N.; Gerringer, F. W.; Gabelich, C. J.; Suffet, I. H. Water Sci. Technol.: Water Supply 2004, 4, 11-18.

(25) Kim, S.; Simpson, A. J.; Kujawinski, E. B.; Freitas, M. A.; Hatcher, P. G. Org. Geochem. 2003, 34, 1325-1335.

(26) Sanchez-Gonzalez, J.; Garcia-Otero, N.; Moreda-Pineiro, A.; Bermejo-Barrera, P. Microchem. J. 2012, 102, 75-82.

(27) Swenson, M. M.; Oyler, A. R.; Minor, E. C. Limnol. Oceanogr.: Methods 2014, 12, 713-728.

(28) Fang, K.; Yuan, D.; Zhang, L.; Feng, L.; Chen, Y.; Wang, Y. Anal. Methods 2014, 6, 5519-5526.

(29) Dittmar, T.; Koch, B.; Hertkorn, N.; Kattner, G. Limnol. Oceanogr.: Methods 2008, 6, 230-235.

(30) Perminova, I. V.; Dubinenkov, I. V.; Kononikhin, A. S.; Konstantinov, A. I.; Zherebker, A. Y.; Andzhushev, M. A.; Lebedev, V. A.; Bulygina, E.; Holmes, R. M.; Kostyukevich, Y. I.; Popov, I. A.; Nikolaev, E. N. Environ. Sci. Technol. 2014, 48, 7461-7468.

(31) Green, N. W.; Perdue, E. M.; Aiken, G. R.; Butler, K. D.; Chen, H.; Dittmar, T.; Niggemann, J.; Stubbins, A. Mar. Chem. 2014, 161, 14-19.

(32) Green, N. W.; McInnis, D.; Hertkorn, N.; Maurice, P. A.; Perdue, E. M. Environ. Eng. Sci. 2015, 32, 38-44.

(33) Flerus, R.; Koch, B. P.; Schmitt-Kopplin, P.; Witt, M.; Kattner, G. Mar. Chem. 2011, 124, 100-107.

(34) Flerus, R.; Lechtenfeld, O. J.; Koch, B.; McCallister, S. L.; Schmitt-Kopplin, P.; Benner, R.; Kaiser, K.; Kattner, G. Biogeosciences 2012, 9, 1935-1955.

(35) Tziotis, D.; Hertkorn, N.; Schmitt-Kopplin, P. Eur. Mass Spectrom. 2011, 17, 415-421.

(36) Thurman, E. M.; Mills, M. S. Solid-Phase Extraction: Principles and Practice; Wiley: New York, 1998.

(37) Shabarova, T.; Villiger, J.; Morenkov, O.; Niggemann, J.; Dittmar, T.; Pernthaler, J. FEMS Microbiol. Ecol. 2014, 89, 111-126. 
(38) Kördel, W.; Dassenakis, M.; Lintelmann, J.; Padberg, S. Pure Appl. Chem. 1997, 69, 1571-1600.

(39) Shakeri Yekta, S.; Gonsior, M.; Schmitt-Kopplin, P.; Svensson, B. H. Environ. Sci. Technol. 2012, 46, 12711-12719.

(40) McIntyre, C.; McRae, C. Org. Geochem. 2005, 36, 543-553.

(41) Gonsior, M.; Hertkorn, N.; Conte, M. H.; Cooper, W. J.; Bastviken, D.; Druffel, E.; Schmitt-Kopplin, P. Mar. Chem. 2014, 163, $10-18$.

(42) Sandron, S.; Rojas, A.; Wilson, R.; Davies, N. W.; Haddad, P. R.; Shellie, R. A.; Nesterenko, P. N.; Kelleher, B. P.; Paull, B. Environ. Sci.: Processes Impacts 2015, 17, 1531-1567.

(43) Perdue, E. M.; Hertkorn, N.; Kettrup, A. Anal. Chem. 2007, 79, $1010-1021$.

(44) Lam, B.; Baer, A.; Alaee, M.; Lefebvre, B.; Moser, A.; Williams, A.; Simpson, A. J. Environ. Sci. Technol. 2007, 41, 8240-8247.

(45) Hertkorn, N.; Frommberger, M.; Witt, M.; Koch, B. P.; SchmittKopplin, P.; Perdue, E. M. Anal. Chem. 2008, 80, 8908-8919. 